ARTICLE

\title{
OM14 is a mitochondrial receptor for cytosolic ribosomes that supports co-translational import into mitochondria
}

Chen Lesnik ${ }^{1}$, Yifat Cohen ${ }^{2}$, Avigail Atir-Lande ${ }^{1}$, Maya Schuldiner $^{2} \&$ Yoav Arava ${ }^{1}$

It is well established that import of proteins into mitochondria can occur after their complete synthesis by cytosolic ribosomes. Recently, an additional model was revived, proposing that some proteins are imported co-translationally. This model entails association of ribosomes with the mitochondrial outer membrane, shown to be mediated through the ribosomeassociated chaperone nascent chain-associated complex (NAC). However, the mitochondrial receptor of this complex is unknown. Here, we identify the Saccharomyces cerevisiae outer membrane protein OM14 as a receptor for NAC. OM144 mitochondria have significantly lower amounts of associated NAC and ribosomes, and ribosomes from NAC[ $\Delta]$ cells have reduced levels of associated OM14. Importantly, mitochondrial import assays reveal a significant decrease in import efficiency into OM144 mitochondria, and OM14-dependent import necessitates NAC. Our results identify OM14 as the first mitochondrial receptor for ribosome-associated NAC and reveal its importance for import. These results provide a strong support for an additional, co-translational mode of import into mitochondria.

\footnotetext{
${ }^{1}$ Department of Biology, Technion-Israel Institute of Technology, Haifa 3200003, Israel. ${ }^{2}$ Department of Molecular Genetics, Weizmann Institute of Science, Rehovot 7610001, Israel. Correspondence and requests for materials should be addressed to Y.A. (email: arava@technion.ac.il).
} 
$\mathrm{M}$ itochondria contain several hundred proteins that are critical for their diverse functions. Most of these proteins are encoded in the nucleus, synthesized in the cytoplasm and imported into mitochondria through their import complexes (TOM and TIM complex) ${ }^{1}$. The import process of most mitochondrial proteins can occur following their complete synthesis in the cytosol (that is, posttranslationally) and the mechanisms for such a process are well established (reviewed in refs 2-4). An additional model, in which proteins are imported while being translated (co-translationally) was proposed $\sim 40$ years ago following the detection of translationally active ribosomes near the mitochondrial outer membrane ${ }^{5,6}$. This model was abandoned for many years and was recently revived following diverse observations (reviewed in refs $7,8)$. In particular, genome-wide microarray analyses revealed that many messenger RNAs are associated with the mitochondrial outer membrane, and advanced microscopic techniques provided important confirmation of these results ${ }^{9-12}$. These mRNAs were proposed to be translated locally (that is, near mitochondria), thereby positioning the emerging polypeptide chain in close proximity to the TOM complex and facilitating import. Indeed, treatments with various translation inhibitors or changes in various coding domains affected mRNA association, thereby supporting the hypothesis that mRNA association is linked to translation $^{10,12-15}$. Furthermore, we have shown that deletion of Tom20, a protein receptor for incoming precursor proteins, affects mRNA association ${ }^{10}$. This result provides an important link between protein import and mRNA association, which can be explained by a co-translational mode of import. Yet, direct support for co-translational import is still scarce. Moreover, the proteins that may be involved in such a process are largely unknown.

The nascent chain-associated complex (NAC) is a ribosomeassociated chaperone that is conserved from yeast to human ${ }^{16}$. It binds ribosomes in close proximity to the protein exit tunnel, and interacts with newly synthesized proteins as they exit the ribosome ${ }^{17}$. NAC was shown to support protein transport to various cellular destinations, including mitochondria ${ }^{18,19}$. The $\alpha$ subunit of NAC (the Egd2 protein in the budding yeast $S$. cerevisiae) can dimerize either with a $\beta 1$ (Egd1 in yeast) or $\beta 3$ (Btt1 in yeast) subunit, thereby forming two different heterodimers ${ }^{20-22}$. One of the two NAC heterodimers was shown to associate preferentially with nascent chains of mitochondria-targeted ribosome-nascent-chain complexes $(\mathrm{RNCs})^{22}$. In vitro studies have shown that NAC can promote protein import when preformed RNCs are mixed with purified mitochondria ${ }^{23,24}$ and deletion of NAC subunits in yeast cells reduced ribosomal association with mitochondria ${ }^{25}$. Furthermore, in vivo studies have shown that co-translational import of mitochondrial fumerase is lower upon NAC deletion ${ }^{26}$. Thus, NAC is a mediator of ribosomes' association with mitochondria, and a critical player in co-translational import. Notably, association of NAC with mitochondria was shown to necessitate a mitochondrial receptor ${ }^{24}$, however, such a receptor has not yet been identified. Furthermore, the two trivial candidates (the protein receptors Tom20 and Tom70) were specifically excluded ${ }^{24}$.

In this work, we perform a genome-wide protein complementation screen for proteins that interact with either NAC subunit. We find the mitochondria outer membrane protein OM14 to be a positive partner. OM14 appeared to interact with NAC in all eight different types of screen that we performed. Co- immunoprecipitation analyses confirmed these results. Furthermore, the mitochondrial fraction from OM14-deleted cells had significantly reduced levels of associated NAC and ribosomes. Complementary to this result, ribosomes from NAC-deleted cells had reduced
OM14 association. Through import assays into mitochondria, we show that OM14-deleted mitochondria have reduced co-translational import efficiency, and this role in import is exerted through NAC. Thus, OM14 is a receptor for ribosome-associated NAC, thereby coordinating localized translation and import into the mitochondria.

\section{Results}

NAC interacts with OM14. The NAC complex was previously shown to support association of ribosomes with mitochondria in a manner that necessitated a mitochondrial receptor ${ }^{24,25,27}$. To identify a possible receptor for NAC (and hence ribosomes) on the mitochondrial outer membrane, we performed a genomewide protein complementation assay (PCA) by utilizing the split dihydrofolate reductase (DHFR) system ${ }^{28}$ (Fig. 1a). In this system, a haploid yeast strain expressing NAC subunit fused to one half of DHFR protein (bait) is mated into a library of $\sim 6,000$ strains, each expressing a different yeast protein fused to the other half of DHFR (prey). Interaction between the bait and a candidate prey brings the two DHFR halves to a close proximity and renders the cells resistant to methotrexate. We performed such a screen with either the $\alpha$-subunit of NAC (Egd2) or the $\beta$-subunit (Egd1) as baits. Each subunit was expressed in either a or $\alpha$ mating type with either $\mathrm{N}^{\prime}$ or $\mathrm{C}^{\prime}$ halves of DHFR, respectively) and mated with a library of the reciprocal mating type. Colonies were then grown on either glucose or galactose as carbon source. This resulted in eight different screens (two baits $\times$ two mating types $\times$ two growth media). Diploids of each screen were allowed to grow for 3 days on methotrexate and colony size was measured with the Balony program ${ }^{29}$. The list of strains that passed our threshold of confidence (were larger than 150 pixels) is shown in Supplementary Table 1 . The only mitochondrial membrane protein that appeared in the largest 100 colonies was OM14, an outer membrane protein with an unknown function ${ }^{30}$. The high ranking of OM14 occurred in each of the eight screens, corroborating the validity of the interaction (Supplementary Table 1). These results were re-confirmed by mating only these strains and their controls (Fig. 1b).

To validate the PCA results by an alternative approach, we performed co-immunoprecipitation analysis (co-IP). OM14 gene was tagged with HA through homologous recombination. Cells expressing an HA-tagged OM14 were lysed in the presence of a detergent (to disassociate OM14 from mitochondrial membranes), and immunopurified with anti-HA beads. Western analysis with antibodies recognizing the Egd2 subunit of NAC revealed significant amounts at the IP fraction (Fig. 1c,d). This co-purification is not due to non-specific binding to the beads because it does not present when a strain expressing untagged OM14 was used or when an unrelated protein (HXK1) was tested.

In summary, the systematic PCA analysis uncovered a novel physical interactor for the NAC on the surface of mitochondria. Such an interaction could mediate NAC targeting to the surface of mitochondria.

Importance for association of ribosomes with mitochondria. We next wished to determine if the interaction between NAC and OM14 is important for the association of ribosomes with mitochondria. To this end, we isolated a crude mitochondrial fraction from cells either expressing or devoid of OM14, and examined the amounts of NAC associated with this fraction by western analysis. Indeed, there was a significant reduction in the amount of NAC that appeared in the mitochondrial fraction of cells deleted for OM14. This is not due to reduced amounts of mitochondria in the OM14A sample, as the levels of another outer 

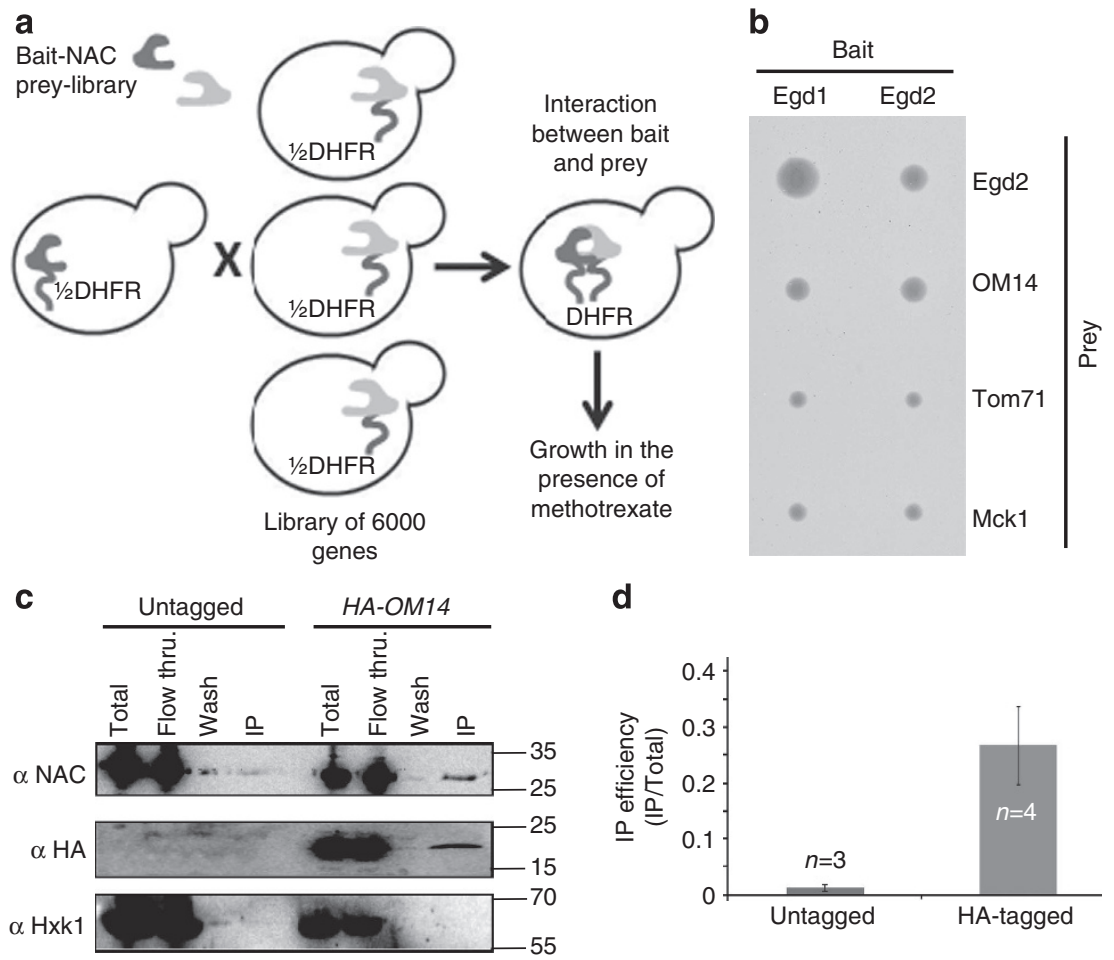

Figure 1 | OM14 interacts with NAC. (a) Scheme of the PCA screen. Yeast strain expressing a bait protein fused to the amino (N)-terminal half of DHFR is mated with a library of yeast strains, each expressing a prey ORF fused to the carboxy (C)-terminal half of DHFR. Mating is done automatically, and the resulting cells are plated in an ordered manner of methotrexate-containing plates. Proximity of the two DHFR halves allows cells' growth in the presence of methotrexate. Colonies size are determined with Balony program after 3 days of growth and compared with cells that express only the DHFR halves. (b) Example of selected interactions with NAC members, Egd1 and Egd2. Egd2 is known to heterodimerize with Egd1, Tom71 serves as a control for other mitochondria outer membrane proteins and Mck1 is a cytosolic kinase that serves as a standard negative control in such assays. (c,d) Co-immunoprecipitation analysis. Strains expressing either untagged or HA-tagged OM14 were subjected to immunoprecipitation (IP) with anti-HA beads, and samples from different steps of isolation were analysed by western blot with the indicated antibodies. Total indicates sample before mixing with the beads, Flow Thru. (flow through) is a sample from the unbound material, Wash indicates sample from the last wash of beads and IP is the eluted material from the beads. The histogram (d) presents the average results of NAC co-IP efficiency, calculated as the IP/input ratio for NAC divided by HA-OM14 ratio. Data are from at least three independent biological replicates ( $n$ ), each entailing the entire procedure described above, from cell growth to western analysis. Error bars represent s.e.m. $P$ value $=0.028$ (independent-samples one-sided $t$-test). Normal distribution was verified by standard tests (either Shapiro-Wilk or Kolmogrov-Smirnov).

membrane protein (Tom20) or a luminal protein (Hsp60) appear similar (Fig. 2a). We note that there are still detectable levels of NAC in OM14A mitochondria fraction. These may be due to some impurities (for example, ER components) in this fraction, or due to activity of other receptors that compensate for OM14 deletion. A marker for ribosome association (Rpl3) appeared almost unchanged (not shown), probably because our crude mitochondrial fraction contains also significant amount of ER-bound ribosomes, which are not affected from OM14 deletion.

To test for impact on ribosomal association with mitochondria more precisely, we established an association protocol that utilize highly purified mitochondria (Fig. 2b) and ribosomes (see Methods). Mitochondria were separated from ER by density centrifugations through a sucrose gradient (Fig. 2b). To ensure that the only NAC source is the ribosome-associated one, mitochondria samples were purified from cells deleted of NAC. We note that this purification protocol necessitates disassembly of ribosomes (routinely imposed by the Zymolyase treatment or by the addition of ethylenediaminetetraacetic acid (EDTA) $)^{31}$, leading to the absence of ribosomes in the mitochondria fraction. Any attempt to maintain ribosomes with mitochondria hinders the separation of the ER from mitochondria ${ }^{31}$. Ribosomestripped mitochondria from either $\mathrm{OM}_{14}{ }^{+}$or OM144 cells were incubated with ribosomes that were cleared from heavy complexes (for example, mitochondria or microsomes) through differential centrifugation. Mixed mitochondria and ribosomes were then centrifuged at $10,000 \mathrm{~g}$ (Fig. 2c), as under these conditions ribosomes are maintained in the supernatant, unless mitochondria are present (Fig. 2c, lanes 5 and 6). Quantitation of ribosomes' sedimentation (by the Rpl3 signal normalized to the Tom 20 signal), reveals at least twofold higher ribosomal association with mitochondria that contain OM14 (Fig. 2c).

We reasoned that the twofold higher association might be even higher if ribosomes were loaded with a mitochondrial targeting sequence (MTS). We, therefore, purified ribosomes from an in vitro translation reaction, that was performed in the presence of a transcript encoding a mitochondria protein (MDH1t). This transcript did not contain a stop codon, to improve ribosomes stalling on the transcript ${ }^{24,32}$ (see also Methods). Indeed, ribosomes association with $O M 144$ mitochondria was negligible, and significantly higher in $\mathrm{OM} 14^{+}$mitochondria (Fig. $2 \mathrm{~d} ; P$ value $=0.042$, independent-samples one-sided $t$-test). Thus, an outer membrane-assembled OM14 is capable of increasing ribosome association with isolated mitochondria.

To substantiate that OM14 association is indeed with ribosomes, we performed the complementary analysis, in which we isolated ribosomes and tested for OM14 association. 

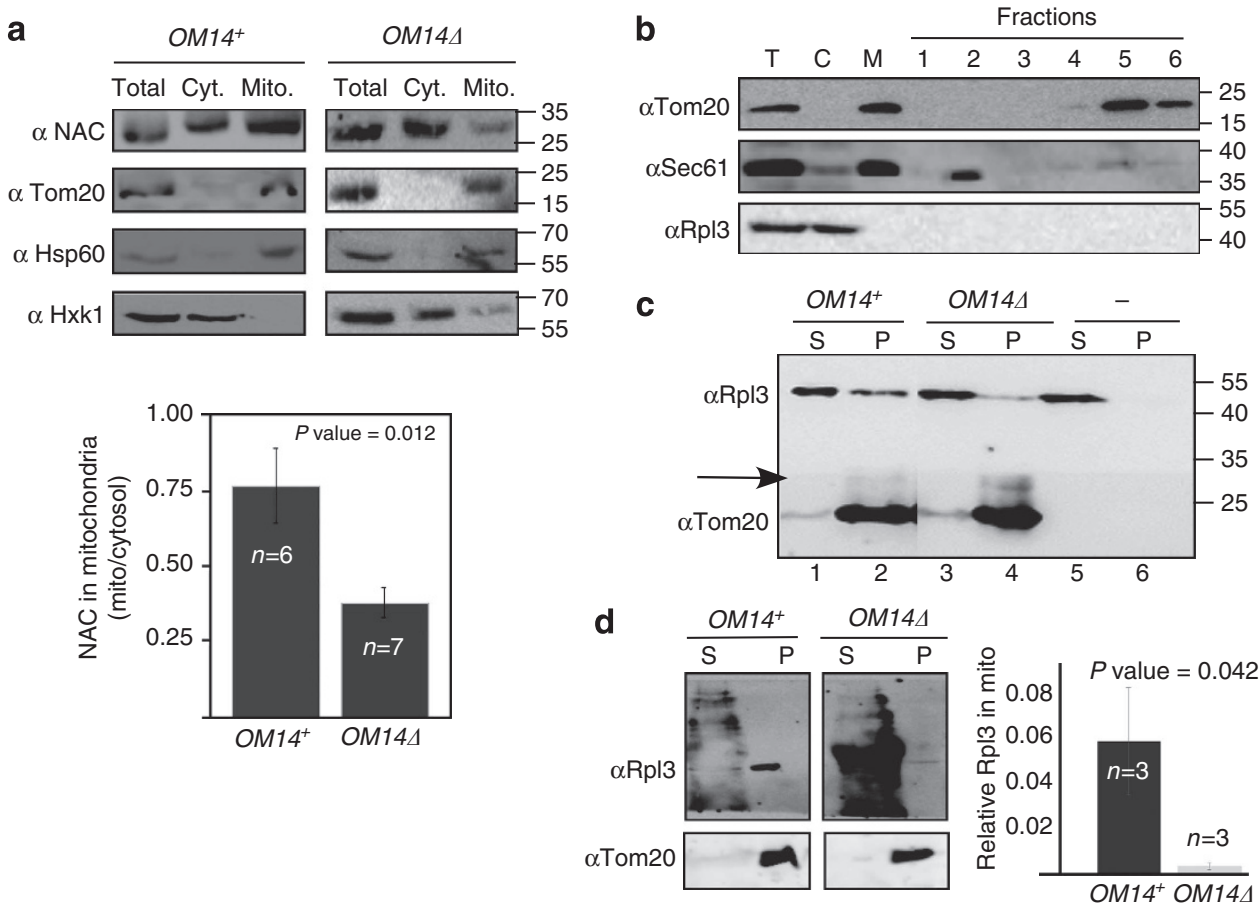

Figure 2 | Decreased NAC and ribosomes association with OM14 4 mitochondria. (a) Cells were subjected to cellular fractionation and samples from the cytosolic (Cyt.) or mitochondrial (Mito.) fractions were subjected to western analysis with the indicated antibodies. The histogram presents the average of the ratio between NAC signals in the two fractions from several independent biological repeats ( $n$ ), each entailing the entire procedure, from cells' growth to western analysis. Error bars represent s.e.m. $P$ value was calculated by independent-samples one-sided $t$-test. Normal distribution was verified by standard tests (either Shapiro-Wilk or Kolmogrov-Smirnov). (b) Purification of mitochondria depleted of ER or ribosomes. Following translational arrest, cell lysate $(T)$ was prepared in the presence of EDTA and separated into cytosolic (C) and membrane (M) fractions by differential centrifugation. The M fraction was further separated through a sucrose gradient into six fractions. Aliquot from each fraction was subjected to western analysis with the indicated antibodies. (c) ER and ribosome-depleted mitochondria were isolated either from OM14 ${ }^{+}$or OM144 cells, incubated with ribosomes and subjected to centrifugation. Sup $(S)$ and pellet $(P)$ samples were analysed by western blot with the indicated antibodies. The arrow indicates the horizontal line in which the membrane was cut, to allow simultaneous incubation with the indicated primary antibodies. Also, unrelated lane was cropped between lanes 2 and 3. (d) Ribosomes with a nascent chain of mitochondria protein (MDH1) were incubated with mitochondria and separated to $\mathrm{S}$ and $\mathrm{P}$, as above. Samples were analysed by western blot with the indicated antibodies. The presented panels are from the same image, that was cropped to remove unrelated lanes. Histograms present the results of three independent biological repeats and statistics were calculated as above. $Y$ axis is the $(P / P+S)$ signal for Rpl3, normalized to the signal of Tom20.

Yeast cells were lysed in the presence of detergent to disassemble mitochondria membranes and ribosomes were isolated by differential centrifugation. The association of HA-tagged OM14 was tested by western analysis (Fig. 3). We found that significant amounts of OM14 co-sedimented in the ribosomal pellet prepared from WT cells, unlike other mitochondrial membrane proteins such as Tom20. Importantly, when ribosomes were devoid of NAC (that is, isolated from NACA strain (egd1$\Delta e g d 2 \Delta)$ ), significantly lower amounts of OM14 co-sedimented. This is not due to lower amounts of ribosomes in this preparation, as the levels of ribosomal marker (Rpl3) appear similar. Intriguingly, the levels of Tom20 appear to be highly induced in NACA cells, while the levels of Rpl3 appear similar. This may suggest a compensation mechanism that is activated upon the absence of this ribosome-associated complex. Overall, these results confirm that NAC interacts specifically with OM14. More important, they reveal that NAC-OM14 interaction occurs while NAC is associated with ribosomes, consistent with NAC being almost exclusively ribosome-associated ${ }^{19,33}$.

OM14 supports import to mitochondria. The functional role of OM14 is unknown. Considering its interaction with NAC, we sought to determine if it has a role in co-translational protein import to the mitochondria. We generated ribosome-nascent chain (RNC) complexes in a rabbit reticulocyte lysate by utilization of a truncated MDH1 construct (MDH1t) that induce ribosome stalling at the end of the $\mathrm{mRNA}^{24,32}$. RNCs were isolated from the lysate by centrifugation through a sucrose cushion $^{34,35}$, and indeed rRNA of both ribosomal subunits was detected in the pellet (Fig. 4a). To confirm the functionality of these RNCs, they were mixed with highly purified mitochondria (that is, depleted of ribosomes or ER marker) ${ }^{36}$ (Fig. 2b), and import of MDH1t was allowed (Fig. 4b); imported MDH1t appears as a shorter protein (due to cleavage of the leader sequence) when proteins are resolved on gel. This shorter band does not appear when membrane potential is diminished by the addition of valinomycin $(-\Delta \Psi)$ and is protected from cleavage by proteinase $\mathrm{K}$ (see also Fig. 4c). About $60 \%$ of the protein appeared to co-sediment with mitochondria, half of it appeared as a shorter band in the gel. This reveals that the RNCs are functional and permit protein association and insertion into mitochondria, at least up to a point that allows cleavage by the mitochondrial peptidase. Importantly, when the same experiment was performed in the presence of EDTA, which disassembles ribosomes, a significant reduction in import was observed (Fig. 4b). This strongly suggests that import occurs while ribosomes are in complex with the nascent chain. 

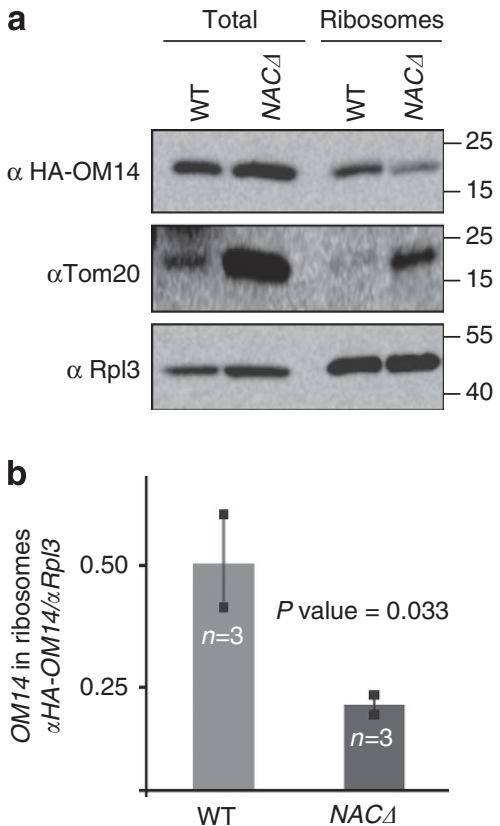

Figure 3 | Lower OM14 association with NACA ribosomes. Ribosomes were isolated from cells either expressing or deleted of NAC genes. A sample before isolation (total) or after centrifugation steps (ribosomes) was analysed by western analysis with the indicated antibodies. The histogram presents the average ratio of signals from several independent biological repeats ( $n$ ) each entailing the entire procedure, from cells' growth to western analysis. Error bars represent s.e.m. $P$ value was calculated by independent-samples one-sided $t$-test. Normal distribution was verified by standard tests (either Shapiro-Wilk or Kolmogrov-Smirnov).

To test if OM14 contributes to co-translational import, we performed time-course import assay with RNCs and mitochondria purified from OM14A strain or its parental strain. These strains were also deleted of NAC, to ensure that the only source of NAC is from the RNCs. More than twofold decrease in import efficiency was observed in mitochondria deleted of OM14 (Fig. 4c-e) compared with mitochondria that contain OM14. The slope of the best-fit linear curve, which is a proxy to import rate, is more than twice lower in OM144 mitochondria compared with $\mathrm{OM} 14^{+}$cells (Fig. 4e). We note that OM14 is not essential for import, as even in its absence there is some import of MDH1t. This is not surprising as OM14 is not a core import component, thus is more likely to have an auxiliary role. This is consistent with OM14 being non-essential for yeast viability, even under respiration-dependent conditions (Supplementary Fig. 1) ${ }^{30}$

We further tested whether OM14 affects import of fully synthesized proteins (that is, post-translationally). For that, we synthesized MDH1 from its full open reading frame (ORF; MDH1f), leading to a complete synthesis of the protein, without ribosome stalling ${ }^{37}$. As these import reactions do not rely on functional RNCs, their efficacy and quality is much higher (Fig. 4f). The mitochondrial preps that are used for the posttranslational import assay are the same as the ones that are used for the co-translational assays, thus these results validate the integrity of the mitochondria and their import potency. Comparing the post-translational import of $\mathrm{OM}_{14}{ }^{+}$to $\mathrm{OM} 144$ mitochondria from multiple experiments, revealed an insignificant small decrease in import $(P$ value $=0.33$, independent-samples one-sided $t$-test). Thus, OM14 impact appears to be specific for the co-translated MDH1. Intriguingly, when import reactions were performed with a commonly used chimeric Su9-DHFR protein (Supplementary Fig. 2), a more significant decrease was observed in OM144 mitochondria. Although this may suggest that OM14 have a differential impact on post-translational import of proteins, a larger repertoire of proteins, preferably native ones need to be tested. Overall, however, these data reveal that OM14 contributes to co-translational import to yeast mitochondria.

OM14 role in import is exerted through NAC. To validate that OM14 necessitates NAC to exert its function, we assembled import complexes that lack NAC, and then introduced NAC to the import assay. NAC-depleted RNCs were obtained by centrifugation of the RNCs through a sucrose cushion supplemented with high salt concentration ( $0.8 \mathrm{M} \mathrm{KAc}$; ref. 34). Western analysis with anti- $\alpha \mathrm{NAC}$ confirmed that NAC is depleted from the RNC pellet and maintained in the supernatant (Supplementary Fig. 3a). Consistent with previous studies, these NAC-depleted RNCs showed much lower import efficiency into mitochondria (Supplementary Fig. 3b-d) ${ }^{24}$.

We then added to the import reaction NAC from three different sources: First, an aliquot of the rabbit reticulocyte lysate high salt wash, which contains NAC, was added. As can be seen in Fig. 5a-c, import was much more significant if mitochondria contained OM14. Second, we purified ribosome-associated proteins (see Methods) either from WT or NACA yeast cells. The NAC-containing sample significantly improved import over the NACA extract (Supplementary Fig. 4a, lanes 1-6), consistent with its known role in improving import into mitochondria ${ }^{24}$. This effect, however, was significantly reduced in mitochondria that lack OM14 (Fig. 5d-f and Supplementary Fig. 4a). Third, the NAC complex was purified to a high level from bacteria (Supplementary Fig. 4b), and added to the import reaction (Fig. 5g and Supplementary Fig. 4c,d). The bacterially purified complex improved import efficiency to $\mathrm{OM} 14^{+}$mitochondria (Supplementary Fig. 4d lanes 2-7). However, the contribution of NAC to import was much lower when OM14 was absent (Fig. 5g and Supplementary Fig. 4c,d). We note that the latter data are presented only in a qualitative manner as low signals hindered reliable quantification of the impact of the bacterially purified NAC. Nevertheless, in at least three experimental repeats, the same pattern was observed (Supplementary Fig. 4c,d). Thus, the overall data from the three sources of NAC strongly suggest that OM14 exerts its function on mitochondrial import through the NAC complex.

\section{Discussion}

Our data provide two critical features in establishing that cotranslational import into mitochondria occurs (Fig. 6): first, we identify a novel receptor for NAC (and hence ribosomes) on the mitochondrial outer membrane. Second, we assign a functional significance to this receptor, namely supporting co-translational import into mitochondria.

A receptor for NAC on the mitochondrial outer membrane was proposed 15 years ago ${ }^{24}$, yet was never identified. Our data clearly show that OM14 is critical for NAC association with mitochondria and may serve as its primary receptor. The molecular details of OM14-NAC interaction are yet to be resolved. Interaction may be direct, presumably through the cytoplasmic domains of OM14 (amino acids 1-38 and 90-104; ref. 30) and one of the NAC subunits. Alternatively, OM14 may necessitate an additional protein to stabilize its interaction with NAC, in a mode that resembles the SRP receptor, which is a heterodimer of a small, membrane-embedded protein (SR $\beta$ ) and a large, mostly cytosolic protein (SR $\alpha$ ), which interacts with SRP ${ }^{38}$. We find the latter more likely, and a screen for OM14-interacting proteins is underway. 
The clear impact of OM14 deletion on protein import, and the contribution of NAC to this process, strongly suggests that the association between NAC and OM14 is important for cotranslational import of proteins into mitochondria (Fig. 6). We suggest that translating ribosomes associate with mitochondria through interaction between NAC and OM14. As NAC interacts with the nascent chains of many proteins, the association with OM14 may be important for initiating specificity for those that are destined to mitochondria. Once association is established, the growing peptide interacts with the import machinery (the TOM complex) and is imported into mitochondria. At least one TOM component (Tom20) was previously shown to be involved in mRNA association with mitochondria, in a translation-dependent manner ${ }^{10}$. Furthermore, the increased levels of Tom 20 in NACA cells (Fig. 3) may indicate a compensation mechanism, which maintains sufficient import efficiency. Import rates in a strain deleted of both Tom 20 and OM14 are yet to be determined.

It is difficult to appreciate the relative contributions of posttranslational and co-translational protein import to mitochondria. Under standard experimental conditions, when steady-state protein levels are measured, these two processes seem redundant (for example, knockout of key factors does not affect cellular growth). Considering the importance of mitochondrial function to cellular physiology, it is not surprising that cells induce various mechanisms to maintain sufficient amounts of protein in mitochondria. Nevertheless, we speculate that co-translational import is the preferred mode under most natural conditions as it enables efficient and rapid import. Furthermore, it minimizes the chances of protein ectopic expression or the need for an elaborate net of chaperones.

The complete repertoire of proteins that are imported cotranslationally is yet unknown. Genome-wide studies of mRNAs association with mitochondria identified many candidates $9,10,13,14$, yet direct impact on mitochondrial activity was rarely demonstrated ${ }^{39,40}$. This strongly suggests that both co- and post-translational import mechanisms apply to most proteins, and post-translational import maintains mitochondrial activity when co-translational import is affected. The fact that the same protein can be imported by either way complicates determination of the contribution to the import of each mode. It may, therefore, be necessary to intervene with the post-translational pathway to expose the in vivo importance of co-translational import. Nevertheless, we cannot exclude the possibility that cotranslational import is applicable only to a subset of proteins. Indeed some specificity in NAC activity was inferred from a genome-wide association study ${ }^{22}$. Thus, NAC may recognize and interact with a subset of emerging peptides. Once NAC interacts with a proper nascent chain, it will be in a better position for interaction with OM14, thereby stabilizing it with the outer membrane.

In this work, we identified a long-sought-after receptor for the ribosome-associated complex NAC. Importantly, we found a a

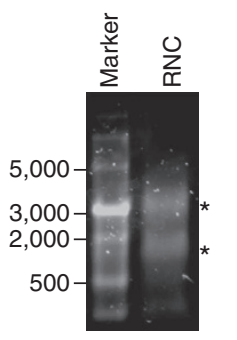

b

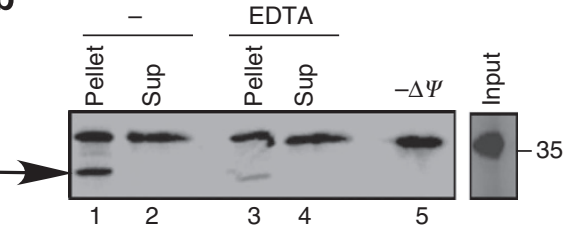

C

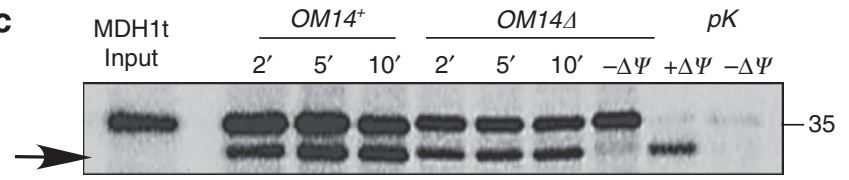

d

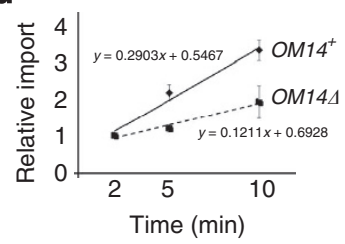

e

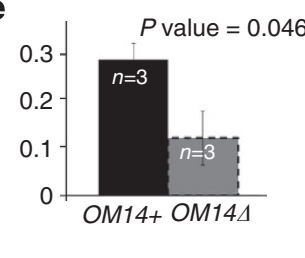

$\mathbf{f}$
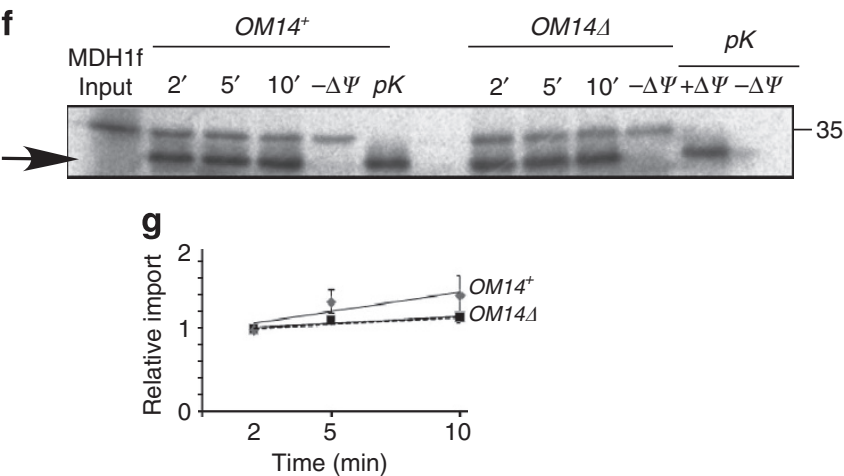

Figure 4 | OM144 mitochondria exhibit lower co-translational import efficiency. (a-e) Co-translational import of MDH1t precursor: (a) Stalled ribosome-nascent chains complexes were isolated by centrifugation through a sucrose cushion and mixed with highly purified mitochondria. Ethidium bromide staining of pelleted RNCs is presented. Bands at the sizes of rRNAs of the small and large subunit are indicated by asterisks. (b) RNCs labelled by ${ }^{35} \mathrm{~S}$-Met were mixed with highly purified mitochondria (fraction five in Fig. 2b) and incubated for 5 min with or without 20 mM EDTA. Mitochondria were then isolated by centrifugation and proteins associated with mitochondria (pellet) or not (sup) were resolved on PAGE. The arrow indicates a protein that was inserted into the mitochondria and cleaved (hence it is shorter). This band is not detected in the $(-\Delta \Psi)$ control reaction in which the membrane potential was diminished. Input panel is a sample from the protein labelling reaction before mixing with mitochondria. (c) MDH1t RNCs were mixed with highly purified mitochondria from $\mathrm{OM}_{14}{ }^{+}$or OM144 cells. At the indicated time points, an aliquot was set aside and resolved on PAGE and phosphorimager. Control reactions included the addition of $1 \mu \mathrm{g} \mathrm{ml}^{-1}$ of valinomycin $(-\Delta \Psi)$ during a $10 \mathrm{~min}$ reaction or addition of proteinase $\mathrm{K}(\mathrm{pK})$ at the end of a $10 \mathrm{~min}$ import reaction, to remove non-imported bands. (d) Import assays were repeated three times ( $n)$, with three time-point measurements in each. Every repeat entailed a new mitochondria prep and a new RNC prep. The average value and s.e.m. for each time point is presented. Graphs are the best-fit linear slope. (e) The histogram presents the average and s.e.m of the best-fit slopes from the three $(n)$ independent experiments. $P$ value was calculated by independent-samples one-sided $t$-test. Normal distribution was verified by standard tests (either Shapiro-Wilk or Kolmogrov-Smirnov). (f,g) Posttranslational import: Full-length $\mathrm{MDH} 1(\mathrm{MDH} 1 \mathrm{f})$ was synthesized from its normal ORF in a rabbit reticulocyte lysates with ${ }^{35} \mathrm{~S}$-Met. Import assays were performed as above, with the indicated controls. Panel e presented the results of three biological repeats, with three time-point measurements in each. Every repeat entailed new mitochondria prep and a new protein synthesis reaction. The average value and s.e.m. for each time point is presented. Graphs are the best-fit linear slope. No statistically significant difference is apparent between the linear best fits of graphs ( $P$ value $=0.33$, independent-samples one-sided $t$-test). 
a

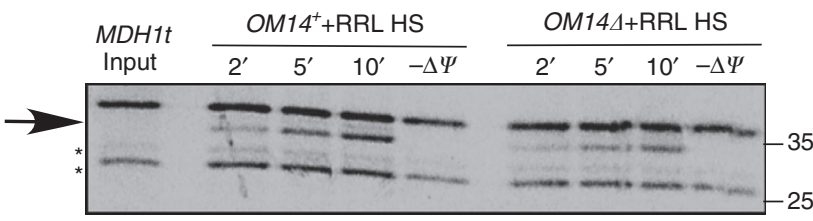

b

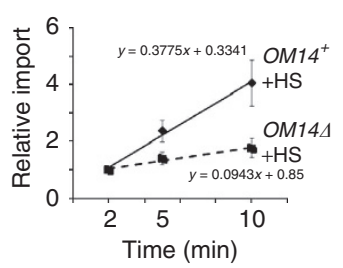

C

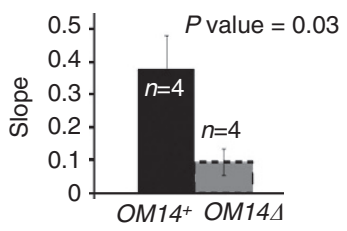

d

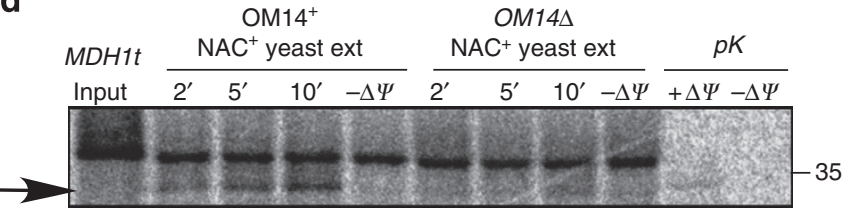

e

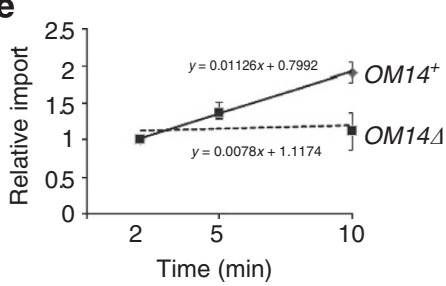

f

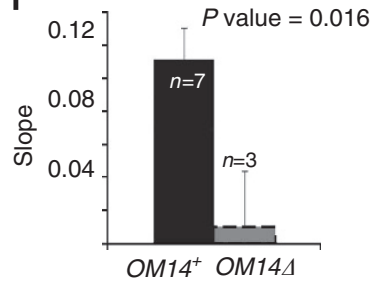

9

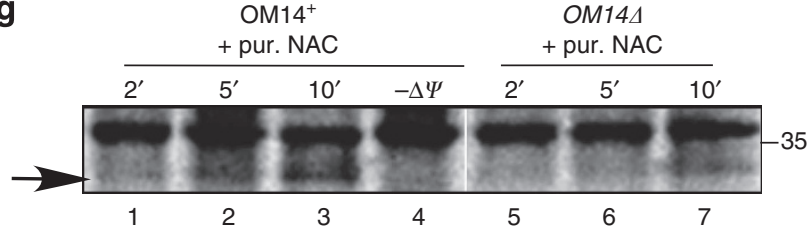

Figure 5 | OM14 necessitates NAC to exert its role. (a-c) NAC from rabbit reticulocyte lysates (RRL): MDH1t RNCs depleted of NAC were mixed with mitochondria purified from either $\mathrm{OM}^{+}{ }^{+}$or $\mathrm{OM} 144$ cells. The import reactions were supplemented with NAC-containing high-salt supernatant (HS) from RRL, and at the indicated time points a sample was collected. The arrow indicates the imported protein. Import assays were repeated four times, each time with a new mitochondria prep and a new RNC prep. Graphs (b), histogram (c) and statistics were calculated as described for Fig. 4. (d-f) NAC from yeast: Import assays entailing NACdepleted RNCs and $\mathrm{OM}_{14}{ }^{+}$or OM144 mitochondria were supplemented with ribosome-associated factors, prepared from $\mathrm{NAC}^{+}$yeast strain. Graphs (e), histogram (f) and statistics were calculated as described for Fig. 4. (g) NAC purified from bacteria: Import assays entailing $\mathrm{OM}^{+}{ }^{+}$or OM14 $\triangle$ mitochondria and MDH1t RNCs depleted of NAC, were supplemented with NAC complex that was expressed and purified to a high degree from bacteria (pur. NAC). Samples were collected at the indicated time points, resolved on PAGE and exposed to phosphorimager for 3 days. Panel is from a single image (provided as Supplementary Fig. 4e), which was cropped between lanes 4 and 5 to remove irrelevant lanes.

physiological role for this receptor, namely import of proteins into mitochondria. The data presented herein are the first to show that localized translation (mediated through NAC-OM14 interaction) supports protein import into mitochondria. The amount of proteins that are targeted by this mode and its implication in vivo are yet to be determined. Nevertheless, our data directly

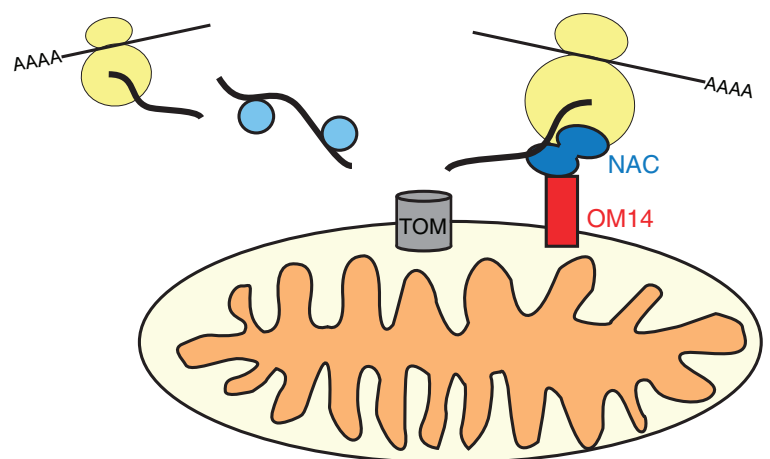

Figure 6 | Two modes for protein import into mitochondria. Depicted to the left is the well-established post-translational import mode, in which chaperones (circles) assist fully translated proteins (black line) in their transport through the TOM complex into the mitochondria ${ }^{49}$. Our results corroborate an additional mode, described on the right. In this model, OM14 interacts with the heterodimeric NAC, while it is associated with translating ribosomes. This interaction brings the emerging protein to proximity with the TOM complex thereby enhancing import. These modes are not mutually exclusive and likely to be redundant under many experimental conditions.

link protein synthesis and mitochondria import, thereby providing a strong support to the idea of co-translational import to mitochondria.

\section{Methods}

Yeast growth and strains. For mitochondrial fractionation and ribosomes isolation, cells were grown in YP-glycerol medium ( $1 \%$ yeast extract, $1 \%$ peptone and $2 \%$ glycerol). Strains are listed in Table 1.

Antibodies. The following antibodies were used: polyclonal anti-EGD2 (Rb1) (1:20,000 dilution), (gift from Professor M. Collart) ${ }^{41}$, polyclonal anti-EGD2 (1:20,000 dilution) (gift from Professor B. Beatrix $)^{42}$, monoclonal anti-HA (1:500 dilution) (gift from Professor A. Aronheim) ${ }^{43}$, polyclonal anti-Tom20 (1:10,000 dilution) (gift from Professor D. Rapaport) ${ }^{44}$ and polyclonal anti Rpl3 (1:5,000 dilution) (gift from Professor J. Warner $)^{45}$.

DHFR-based protein fragment complementation assay. The protein-protein interactions screen was done using the yeast DHFR PCA library according to the published protocol ${ }^{28}$ in 1,536 format. In brief, MATa strains with the ORFs of either Egd1 or Egd2 fused to F[1,2] were mated to the entire MATalpha collection of ORFs tagged with F[3]. The complementary mating was also performed, in which MATalpha strains with the ORFs Egd1 or Egd2 fused to F[3] were mated to the entire MATa collection of ORFs tagged with F[1,2]. The resulting diploids were subsequently selected for growth in the presence of methotrexate for positive DHFR PCA reconstitution for 5 days in $30^{\circ} \mathrm{C}$. The analysis of each plate was done by taking image of the entire plate, which was saved in JPG format at a resolution of 300 d.p.i. Using the freely available Balony software ${ }^{29}$, the area for each colony was extracted and a threshold of a positive interaction was set to be $>150$.

Cell fractionation for import analyses. Crude or highly purified mitochondria were isolated as described ${ }^{36}$, with several modifications: Yeast strains were grown in YP-glycerol medium to $\mathrm{OD}_{600} 1.5-2.0$, pelleted, washed and treated with Zymolyase for $30 \mathrm{~min}$ at $30^{\circ} \mathrm{C}$ with gentle shaking. Spheroplasts were resuspended with $3 \mathrm{ml}$ of ice-cold homogenization buffer $(0.6 \mathrm{M}$ Sorbitol, $10 \mathrm{mM}$ Tris $\mathrm{HCl} \mathrm{pH}$ 7.4, $1 \mathrm{mM}$ EDTA, $1 \mathrm{mM}$ phenylmethyl sulphonyl fluoride (PMSF), $0.2 \%$ bovine serum albumin (BSA), and homogenized by 15 strokes using Dounce homogenizer equipped with tight-fitting pestle. Unbroken cells and nuclei were removed by centrifugation for $6 \mathrm{~min}$ at $4^{\circ} \mathrm{C}$ at $1,500 \mathrm{~g}$. The supernatant was then centrifuged for $10 \mathrm{~min}$ at $4^{\circ} \mathrm{C}$ at $10,000 \mathrm{~g}$ and the crude mitochondrial pellet was frozen in liquid nitrogen. To obtain highly purified mitochondria, the pellet was washed in SEM buffer (250 mM sucrose, $1 \mathrm{mM}$ EDTA, $10 \mathrm{mM}$ MOPS pH 7.2), resuspended

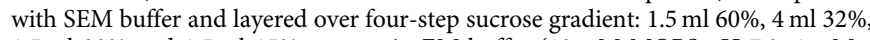
$1.5 \mathrm{ml} 23 \%$ and $1.5 \mathrm{ml} 15 \%$ sucrose in EM buffer (10 mM MOPS pH 7.2, $1 \mathrm{mM}$ 
Table 1 | Yeast strains.

\begin{tabular}{|c|c|c|}
\hline Description & Lab name & Genotype \\
\hline BY4741 (OM14+) & yA1 & Mat $a$, his $3 \Delta 1$, leu2 $\Delta 0$, met15 $\Delta 0$, ura3 $\Delta 0$ \\
\hline Egd1 bait in BY4741 & yA1224 & MATa Egd1-DHFR F[1,2]::NatR his3 $\Delta 1$ leu2 $\Delta 0$ met $15 \Delta 0$ ura3 \\
\hline Egd1 bait in BY4742 & yA1225 & MATalpha Egd1-DHFR F[3]::HygroR his $3 \Delta 1$ leu2 $\Delta 0$ lys $2 \Delta 0 u$ \\
\hline Egd2 bait in BY 4741 & yA1226 & MATa Egd2-DHFR F[1,2]::NatR his $3 \Delta 1$ leu2 $\Delta 0$ met15 $\Delta 0$ ura \\
\hline Egd2 bait in BY 4742 & yA1227 & MATalpha Egd2-DHFR F[3]::HygroR his3 $\Delta 1$ leu2 $\Delta O$ lys $2 \Delta O u$ \\
\hline $\mathrm{OM} 14 \Delta$ & yA1067 & Mat $a$, his $3 \Delta 1$, leu2 $\Delta 0$, met15 $\Delta 0$, ura $3 \Delta 0$, om14::KanR \\
\hline OM14-HA & yA1144 & Mat $a$, his $3 \Delta 1$, leu $2 \Delta 0$, met15 $\Delta 0$, ura $3 \Delta 0$, OM14 $3 X H A-$ sph \\
\hline NAC + & yA318 & Mat a leu2, trp1, his3, ura3, ade2 \\
\hline$N A C \triangle$ & yA321 & Mat a leu2,trp1, his3,ura3, ade2 egd2::ADE2, egd1::URA3 \\
\hline $\mathrm{NAC}+, \mathrm{OM} 14-\mathrm{HA}$ & yA1156 & Mat a leu2, trp1, his4, ura3, OM14 3XHA- spHIS3 \\
\hline$N A C \Delta+$ OM14-HA & yA1155 & $\begin{array}{l}\text { Mat a leu2, trp1, his3, ura3, ade2 egd2::ADE2, egd1::ura3 + } \\
\text { OM14 3XHA- spHIS3 }\end{array}$ \\
\hline$N A C \Delta, O M 14 \Delta$ & yA1167 & Mat a leu2,trp1,om14::spHIS3,egd2::ADE2 , egd1::URA3 \\
\hline
\end{tabular}

Source

Euroscarf

Ref. 28

Ref. 28

Ref. 28

Ref. 28

Euroscarf

Homologous recombination with

pFA6a-3HA-HIS3MX6 (ref. 50) Ref. 26

Ref. 26

YA318 + Homologous recombination with pFA6a-3HA-HIS3MX6 (ref. 50) yA321+ Homologous recombination with pFA6a-3HA-HIS3MX6 (ref. 50) yA321 + Homologous recombination with pFA6a-3HA-HIS3MX6 (ref. 50)
EDTA). The gradient was centrifuged at $134,000 \mathrm{~g}$ at $4^{\circ} \mathrm{C}$ for $1 \mathrm{~h}$ and purified mitochondria were recovered from the $60 \% / 32 \%$ interface. Mitochondria were centrifuged again at $10,000 \mathrm{~g}$ at $4^{\circ} \mathrm{C}$ for $10 \mathrm{~min}$, resuspended in SEM buffer and snap frozen in liquid nitrogen and stored at $-80^{\circ} \mathrm{C}$. Mitochondria were thawed at $25^{\circ} \mathrm{C}$ bath immediately before use and kept on ice.

Ribosomes purification. Ribosome purification is based on the method described in ref. 46. Specifically, yeast strains were grown in $250 \mathrm{ml} \mathrm{YP-glycerol} \mathrm{medium} \mathrm{to}$ $\mathrm{OD}_{600} 1.0-1.5$. Cells were centrifuged at room temperature for $10 \mathrm{~min}$ at $3,000 \mathrm{~g}$ and the pellet was washed in double distilled water. Cells were resuspended in 1.3 volumes of lysis buffer (Ribo buffer (0.1 M KOAc, $20 \mathrm{mM}$ HepesKOH pH 7.4, $\left.2.5 \mathrm{mM} \mathrm{Mg}(\mathrm{OAc})_{2}\right), 1 \mathrm{mg} \mathrm{ml}^{-1}$ heparin, $2 \mathrm{mM}$ dithiothreitol (DTT), $1 \mathrm{mg} \mathrm{ml}^{-1}$ leupeptin, $0.01 \mathrm{mg} \mathrm{ml}^{-1}$ Pepstatin A, $1 \mathrm{mM}$ PMSF, $1 \%$ Triton X-100) and glass beads $(0.4-0.6 \mathrm{~mm})$ were added. Cells were lysed by two pulses of $1.5 \mathrm{~min}$ each in Bead Beater and the lysate was clarified by centrifugation in a Sorval SS-34 rotor at 12,000 r.p.m. for $30 \mathrm{~min}$ at $4^{\circ} \mathrm{C}$. The supernatant was loaded on $2.5 \mathrm{ml}$ of sucrose cushion (Ribo buffer supplemented with $500 \mathrm{mM} \mathrm{KCl}, 1 \mathrm{M}$ sucrose and $2 \mathrm{mM}$ DTT) and centrifuged using Beckman Type 70Ti ultracentrifuge rotor at 60,000 r.p.m. for $106 \mathrm{~min}$ at $4{ }^{\circ} \mathrm{C}$. The ribosomal pellet was resuspended in $300 \mu \mathrm{l}$ storage buffer (Ribo buffer supplemented with $250 \mathrm{mM}$ sucrose and $2 \mathrm{mM}$ DTT) and immediately frozen in liquid nitrogen.

Factors that are associated with yeast ribosomes (for Fig. $5 \mathrm{~d}-\mathrm{f}$ ) were isolated from ribosomes by loading isolated ribosomes on a high-salt sucrose cushion $(25 \%$ sucrose, $20 \mathrm{mM}$ HepesKOH pH 7.4, $2 \mathrm{mM}$ DTT, $2 \mathrm{mM} \mathrm{Mg}(\mathrm{Ac})_{2}, 0.8 \mathrm{M} \mathrm{KAc}$, $2.5 \mu \mathrm{g} \mathrm{ml}^{-1}$ leupeptin, $1.8 \mu \mathrm{g} \mathrm{ml}^{-1}$ Pepstatin A, $5 \mathrm{mM}$ PMSF) and centrifugation at 60,000 r.p.m. for $106 \mathrm{~min}$ at $4^{\circ} \mathrm{C}$ (Beckman Type $70 \mathrm{Ti}$ ). The supernatant was frozen in liquid nitrogen and kept at $-80^{\circ} \mathrm{C}$.

Co-immunoprecipitation. Cells were grown in $200 \mathrm{ml} \mathrm{YP-glycerol} \mathrm{medium} \mathrm{to}$ $\mathrm{OD}_{600} 0.5-1.0$, centrifuged at $4{ }^{\circ} \mathrm{C}$ for $4 \mathrm{~min}$ at $3,000 \mathrm{~g}$ and the pellet was washed twice in buffer A (20 mM Tris $\mathrm{HCl} \mathrm{pH} \mathrm{8,} 140 \mathrm{mM} \mathrm{KCl,} 1.8 \mathrm{mM} \mathrm{MgCl}_{2}, 0.1 \% \mathrm{NP}$ 40). Cells were resuspended in $5 \mathrm{ml}$ buffer B (buffer A supplemented with $0.5 \mathrm{mM}$ DTT, $1 \mathrm{mM}$ PMSF, $10 \mu \mathrm{g} \mathrm{ml}^{-1}$ leupeptin, $7 \mu \mathrm{g} \mathrm{ml}^{-1}$ Pepstatin A, 20 units per ml DNase, $1 \mu \mathrm{g} \mathrm{ml}^{-1}$ aprotinin and $10 \mu \mathrm{g} \mathrm{ml}^{-1}$ trypsin inhibitor) and glass beads $(0.4-0.6 \mathrm{~mm})$ were added. Cells were lysed by two pulses of $1.5 \mathrm{~min}$ each in Bead Beater and the lysate was clarified. One percent of the sample was set aside as 'Total' and the rest of the sample was loaded twice on anti-HA-coupled sepharose column and $1 \%$ was set aside as 'FT' (Flow Through). The column was first washed with buffer B and then twice with washing buffer $(100 \mathrm{mM} \mathrm{NaCl}, 50 \mathrm{mM}$ Tris $\mathrm{HCl}$ $\mathrm{pH} 8,5 \%$ glycerol). Elution sample was collected by adding $0.1 \mathrm{M}$ of acetic acid $\mathrm{pH}$ 3. The acetic acid was dissipated and pellets were resuspended in $100 \mathrm{mM}$ Tris $\mathrm{HCl}$ pH 8 in $1 \times$ SDS loading dye for western blot analysis.

Assessing association of ribosomes with mitochondria. Yeast ribosomes were purified as described in the above section (ribosome purification) including a final step of centrifugation in a low-salt sucrose cushion (25\% sucrose, $20 \mathrm{mM}$ Hepes$\mathrm{KOH} \mathrm{pH} 7.4,2 \mathrm{mM}$ DTT, $2 \mathrm{mM} \mathrm{Mg}(\mathrm{Ac})_{2}, 0.1 \mathrm{M} \mathrm{KAc}, 2.5 \mu \mathrm{g} \mathrm{ml}^{-1}$ leupeptin, $1.8 \mathrm{mg} \mathrm{ml}^{-1}$ Pepstatin A, $5 \mathrm{mM}$ PMSF). The ribosomal pellet was resuspended in Ribo storage buffer (0.1 M KOAc, $20 \mathrm{mM}$ HepesKOH pH 7.4, $2.5 \mathrm{mM} \mathrm{Mg}(\mathrm{OAc})_{2}$, $250 \mathrm{mM}$ sucrose, $2 \mathrm{mM}$ DTT) and cleared of any membrane compartments or large ribosomal complexes by five rounds of centrifugation at $10,000 \mathrm{~g}$ for $5 \mathrm{~min}$. The supernatant from the last centrifugation step was immediately frozen in liquid nitrogen. To test the association of ribosomes with highly purified mitochondria,
$25 \mu \mathrm{g}$ of highly purified mitochondria (prepared as described above) were incubated with $10 \mu \mathrm{g}$ of ribosomes. Incubation was performed for $5 \mathrm{~min}$ at room temperature in mitochondria association buffer (MA buffer: $0.6 \mathrm{M}$ sorbitol, $50 \mathrm{mM}$ HepesKOH pH 7.4, $50 \mathrm{mM} \mathrm{KCl}, 10 \mathrm{mM} \mathrm{MgCl}_{2}, 2 \mathrm{mM} \mathrm{KH}_{2} \mathrm{PO}_{4}, 1 \mathrm{mg} \mathrm{ml}^{-1} \mathrm{BSA}$, $0.75 \mathrm{mg} \mathrm{ml}^{-1}$ methionine and fresh $250 \mathrm{mM}$ creatine phosphate and $5 \mathrm{mg} \mathrm{ml}^{-1}$ creatine kinase, $2 \mathrm{mM}$ ATP, $8 \mathrm{mM}$ NADH in a total volume of $25 \mu \mathrm{l}$ ). Samples were then centrifuged for $5 \mathrm{~min}$ at $10,000 \mathrm{~g}$. Supernatant and pellet were subjected to western analysis.

For assessing the association of RNCs containing mitochondrial protein precursor (Fig. 2d), RNCs were generated as described in the section below (Generating ribosome-nascent chains), and $40 \mu \mathrm{l}$ of RNCs were loaded on $200 \mu \mathrm{l}$ low-salt sucrose cushion (25\% sucrose, $20 \mathrm{mM}$ HepesKOH pH 7.4, $2 \mathrm{mM}$ DTT, $2 \mathrm{mM} \mathrm{Mg}(\mathrm{Ac})_{2}, 0.1 \mathrm{M} \mathrm{KAc}, 2.5 \mu \mathrm{g} \mathrm{ml}^{-1}$ leupeptin, $1.8 \mu \mathrm{g} \mathrm{ml}^{-1}$ Pepstatin A, $5 \mathrm{mM}$ PMSF), centrifuged using Beckman MicroUltra Centrifuge Rotor TLA-120.2 MicroFixed at 95,000 r.p.m. for $30 \mathrm{~min}$ at $4{ }^{\circ} \mathrm{C}$ and the RNCs pellet was suspended with $60 \mu \mathrm{l}$ of MA buffer without BSA. Immediately after isolation, $10 \mu \mathrm{l}$ of RNCs were incubated with $25 \mu \mathrm{g}$ of mitochondria for $5 \mathrm{~min}$ at room temperature in MA buffer. Samples were then centrifuged for $5 \mathrm{~min}$ at $10,000 \mathrm{~g}$ and the supernatant and pellet were subjected to western analysis.

Generating ribosome-nascent chains. Plasmid or PCR product containing a truncated MDH1 gene ${ }^{24}$ was introduced into $\mathrm{T}_{\mathrm{N}} \mathrm{T}$ SP6 Quick Coupled Transcription/Translation System (Promega L2080). Usually, $1 \mu \mathrm{g}$ of DNA was mixed with $40 \mu \mathrm{l}$ of master mix and $2 \mu \mathrm{l}$ of EasyTag Methionine L- $\left[{ }^{35} \mathrm{~S}\right]-\mathrm{NEG}$ 709A500UC. The reaction was incubated for $1.5 \mathrm{~h}$ at $30^{\circ} \mathrm{C}$. The lysate was loaded on sucrose cushion (25\% sucrose, $20 \mathrm{mM}$ HepesKOH pH 7.4, 2 mM DTT, $2 \mathrm{mM}$ $\mathrm{Mg}(\mathrm{Ac})_{2}, 0.1 \mathrm{M} \mathrm{KAc}, 2.5 \mu \mathrm{g} \mathrm{ml}^{-1}$ leupeptin, $1.8 \mu \mathrm{g} \mathrm{ml}^{-1}$ Pepstatin A, $5 \mathrm{mM}$ PMSF) and centrifuged using Beckman MicroUltra Centrifuge Rotor TLA-120.2 MicroFixed at 95,000 r.p.m. for $30 \mathrm{~min}$ at $4{ }^{\circ} \mathrm{C}$. For high-salt wash (Supplementary Fig. 3), the KAc concentration wash increased to $0.8 \mathrm{M}$. The RNCs pellet was washed and resuspended with $60 \mu \mathrm{l}$ of import buffer $(0.6 \mathrm{M}$ sorbitol, $50 \mathrm{mM}$ HepesKOH pH 7.4, $50 \mathrm{mM} \mathrm{KCl}, 10 \mathrm{mM} \mathrm{MgCl}_{2}, 2 \mathrm{mM} \mathrm{KH}_{2} \mathrm{PO}_{4}, 1 \mathrm{mg} \mathrm{ml}^{-1} \mathrm{BSA}$ $0.75 \mathrm{mg} \mathrm{ml}^{-1}$ methionine and fresh $250 \mathrm{mM}$ creatine phosphate and $5 \mathrm{mg} \mathrm{ml}^{-1}$ creatine kinase).

Co-translational import assay. Import assay was performed essentially as described in ref. 47. Briefly, RNCs were mixed with $25 \mu \mathrm{g}$ of mitochondria in import buffer supplemented with $2 \mathrm{mM}$ ATP and $8 \mathrm{mM}$ NADH in a total volume of $300 \mu \mathrm{l}$. At each time point $(2,5$ or $10 \mathrm{~min}), 100 \mu \mathrm{l}$ aliquots were transferred to a new ice-cold tube, $1 \mu \mathrm{g} \mathrm{ml}^{-1}$ of valinomycin was added and the sample was kept on ice. Half of each time point sample was treated with $2.5 \mu \mathrm{g}$ proteinase $\mathrm{K}$ for $15 \mathrm{~min}$ on ice (proteinase $\mathrm{K}$ was inactivated by the addition of PMSF to a final concentration of $2 \mathrm{mM}$ ). Samples were centrifuged at $10,000 \mathrm{~g}$ for $3 \mathrm{~min}$ at $4^{\circ} \mathrm{C}$, mitochondria pellets were washed with SEM buffer $(250 \mathrm{mM}$ sucrose, $1 \mathrm{mM}$ EDTA, $10 \mathrm{mM}$ MOPS pH 7.2) and resuspended with import buffer without BSA and analysed by polyacrylamide gel electrophoresis (PAGE). Radioactive signals were detected by PhosphorImager and quantified with ImageQuant.

Purification of yeast NAC complex from bacteria. Purification of yeast NAC complex (EGD2-EGD1) from bacteria was performed essentially as was previously described in ref. 48. Briefly, the dual expression plasmid pOP-H6-EGD2-EGD1 (pA896) was introduced into Escherichia coli strain MH1 together with a laq-Iq repressor (pA917) (plasmid and bacteria are a gift from Prof. Elke Deuerling). 
Cells were grown at $30^{\circ} \mathrm{C}$ and NAC expression was induced with IPTG for $3 \mathrm{~h}$. Cell lysate was subjected to initial purification on $\mathrm{Ni}^{+2}$ columns (cat. 1018-25, Adar Biotech), utilizing the $\mathrm{His}_{6}$ tag present at the amino (N) terminus of EGD2. Eluted material was further purified by gel filtration size-exclusion column (Superdex 200, GE Healthcare) in buffer that contains $20 \mathrm{mM}$ Tris pH 7, $50 \mathrm{mM} \mathrm{NaCl}$ and $5 \mathrm{mM}$ $\mathrm{MgCl}_{2}$. Both subunits were eluted at a fraction that corresponds to their combined mass (that is, as a formed complex).

Statistical analyses. Statistical analyses were performed with SPSS. For each strain in each experiment, normality of the results was verified using either Shapiro-Wilk or Kolmogrov-Smirnov tests. Variances were calculated and accordingly $P$ values were determined by independent-samples one-sided $t$-test.

\section{References}

1. Wiedemann, N., van der Laan, M. \& Pfanner, N. SnapShot: import and sorting of mitochondrial proteins. Cell 138, 808-808.e1 (2009).

2. Neupert, W. Protein import into mitochondria. Annu. Rev. Biochem. 66, 863-917 (1997).

3. Chacinska, A., Koehler, C. M., Milenkovic, D., Lithgow, T. \& Pfanner, N. Importing mitochondrial proteins: machineries and mechanisms. Cell 138, 628-644 (2009).

4. Rapaport, D. How does the TOM complex mediate insertion of precursor proteins into the mitochondrial outer membrane? J. Cell Biol. 171, 419-423 (2005).

5. Kellems, R. E., Allison, V. F. \& Butow, R. A. Cytoplasmic type 80 S ribosomes associated with yeast mitochondria. II. Evidence for the association of cytoplasmic ribosomes with the outer mitochondrial membrane in situ. J. Biol. Chem. 249, 3297-3303 (1974).

6. Kellems, R. E. \& Butow, R. A. Cytoplasmic type $80 \mathrm{~S}$ ribosomes associated with yeast mitochondria. 3. Changes in the amount of bound ribosomes in response to changes in metabolic state. J. Biol. Chem. 249, 3304-3310 (1974).

7. Ahmed, A. U. \& Fisher, P. R. Import of nuclear-encoded mitochondrial proteins: a cotranslational perspective. Int. Rev. Cell. Mol. Biol. 273, 49-68 (2009).

8. Lithgow, T. Targeting of proteins to mitochondria. FEBS Lett. 476, 22-26 (2000)

9. Marc, P. et al. Genome-wide analysis of mRNAs targeted to yeast mitochondria. EMBO Rep. 3, 159-164 (2002).

10. Eliyahu, E. et al. Tom 20 mediates localization of mRNAs to mitochondria in a translation-dependent manner. Mol. Cell. Biol. 30, 284-294 (2010).

11. Garcia, M. et al. Mitochondria-associated yeast mRNAs and the biogenesis of molecular complexes. Mol. Biol. Cell 18, 362-368 (2007).

12. Gadir, N., Haim-Vilmovsky, L., Kraut-Cohen, J. \& Gerst, J. E. Localization of mRNAs coding for mitochondrial proteins in the yeast Saccharomyces cerevisiae. RNA 17, 1551-1565 (2011).

13. Saint-Georges, Y. et al. Yeast mitochondrial biogenesis: a role for the PUF RNA-binding protein Puf3p in mRNA localization. PLoS ONE 3, e2293 (2008).

14. Eliyahu, E., Lesnik, C. \& Arava, Y. The protein chaperone Ssal affects mRNA localization to the mitochondria. FEBS Lett. 586, 64-69 (2012).

15. Garcia, M., Delaveau, T., Goussard, S. \& Jacq, C. Mitochondrial presequence and open reading frame mediate asymmetric localization of messenger RNA. EMBO Rep. 11, 285-291 (2010).

16. Rospert, S., Dubaquie, Y. \& Gautschi, M. Nascent-polypeptide-associated complex. Cell. Mol. Life Sci. 59, 1632-1639 (2002).

17. Wang, S., Sakai, H. \& Wiedmann, M. NAC covers ribosome-associated nascent chains thereby forming a protective environment for regions of nascent chains just emerging from the peptidyl transferase center. J. Cell Biol. 130, 519-528 (1995).

18. Wiedmann, B., Sakai, H., Davis, T. A. \& Wiedmann, M. A protein complex required for signal-sequence-specific sorting and translocation. Nature 370, 434-440 (1994).

19. George, R., Beddoe, T., Landl, K. \& Lithgow, T. The yeast nascent polypeptideassociated complex initiates protein targeting to mitochondria in vivo. Proc. Natl Acad. Sci. USA 95, 2296-2301 (1998).

20. Reimann, B. et al. Initial characterization of the nascent polypeptide-associated complex in yeast. Yeast 15, 397-407 (1999).

21. Beatrix, B., Sakai, H. \& Wiedmann, M. The alpha and beta subunit of the nascent polypeptide-associated complex have distinct functions. J. Biol. Chem. 275, 37838-37845 (2000).

22. del Alamo, M. et al. Defining the specificity of cotranslationally acting chaperones by systematic analysis of mRNAs associated with ribosome-nascent chain complexes. PLoS Biol. 9, e1001100 (2011).

23. Wiedmann, B. \& Prehn, S. The nascent polypeptide-associated complex (NAC) of yeast functions in the targeting process of ribosomes to the ER membrane. FEBS Lett. 458, 51-54 (1999).

24. Funfschilling, U. \& Rospert, S. Nascent polypeptide-associated complex stimulates protein import into yeast mitochondria. Mol. Biol. Cell 10, 3289-3299 (1999).
25. George, R., Walsh, P., Beddoe, T. \& Lithgow, T. The nascent polypeptideassociated complex (NAC) promotes interaction of ribosomes with the mitochondrial surface in vivo. FEBS Lett. 516, 213-216 (2002).

26. Yogev, O., Karniely, S. \& Pines, O. Translation-coupled translocation of yeast fumarase into mitochondria in vivo. J. Biol. Chem. 282, 29222-29229 (2007).

27. MacKenzie, J. A. \& Payne, R. M. Ribosomes specifically bind to mammalian mitochondria via protease-sensitive proteins on the outer membrane. J. Biol. Chem. 279, 9803-9810 (2004).

28. Tarassov, K. et al. An in vivo map of the yeast protein interactome. Science 320, 1465-1470 (2008).

29. Young, B. P. \& Loewen, C. J. Balony: a software package for analysis of data generated by synthetic genetic array experiments. BMC Bioinformatics 14, 354 (2013).

30. Burri, L. et al. Integral membrane proteins in the mitochondrial outer membrane of Saccharomyces cerevisiae. FEBS J. 273, 1507-1515 (2006).

31. Lesnik, C. \& Arava, Y. Isolation of mRNAs associated with yeast mitochondria to study mechanisms of localized translation. J. Vis. Exp. 85, e51265 (2014).

32. Gilmore, R., Collins, P., Johnson, J., Kellaris, K. \& Rapiejko, P. Transcription of full-length and truncated mRNA transcripts to study protein translocation across the endoplasmic reticulum. Methods Cell. Biol. 34, 223-239 (1991).

33. Raue, U., Oellerer, S. \& Rospert, S. Association of protein biogenesis factors at the yeast ribosomal tunnel exit is affected by the translational status and nascent polypeptide sequence. J. Biol. Chem. 282, 7809-7816 (2007).

34. Lauring, B., Sakai, H., Kreibich, G. \& Wiedmann, M. Nascent polypeptideassociated complex protein prevents mistargeting of nascent chains to the endoplasmic reticulum. Proc. Natl Acad. Sci. USA 92, 5411-5415 (1995).

35. MacKenzie, J. A. \& Payne, R. M. Preparation of ribosomes loaded with truncated nascent proteins to study ribosome binding to mammalian mitochondria. Mitochondrion 6, 64-70 (2006).

36. Meisinger, C., Sommer, T. \& Pfanner, N. Purification of Saccharomcyes cerevisiae mitochondria devoid of microsomal and cytosolic contaminations. Anal. Biochem. 287, 339-342 (2000).

37. Rospert, S. \& Hendrik, O. in Cell Biology Assays: Essential Methods (ed. Kreitzer, G.) 97-107 (2006).

38. Miller, J. D., Tajima, S., Lauffer, L. \& Walter, P. The beta subunit of the signal recognition particle receptor is a transmembrane GTPase that anchors the alpha subunit, a peripheral membrane GTPase, to the endoplasmic reticulum membrane. J. Cell Biol. 128, 273-282 (1995).

39. Margeot, A. et al. In Saccharomyces cerevisiae, ATP2 mRNA sorting to the vicinity of mitochondria is essential for respiratory function. $E M B O$ J. 21, 6893-6904 (2002).

40. Michaud, M. et al. Differential targeting of VDAC3 mRNA isoforms influences mitochondria morphology. Proc. Natl Acad. Sci. USA 111, 8991-8996 (2014).

41. Panasenko, O. O., David, F. P. \& Collart, M. A. Ribosome association and stability of the nascent polypeptide-associated complex is dependent upon its own ubiquitination. Genetics 181, 447-460 (2009).

42. Pech, M., Spreter, T., Beckmann, R. \& Beatrix, B. Dual binding mode of the nascent polypeptide-associated complex reveals a novel universal adapter site on the ribosome. J. Biol. Chem. 285, 19679-19687 (2010).

43. Wasserman, T. et al. A novel c-Jun N-terminal kinase (JNK)-binding protein WDR62 is recruited to stress granules and mediates a nonclassical JNK activation. Mol. Biol. Cell 21, 117-130 (2010).

44. Stan, T. et al. Recognition of preproteins by the isolated TOM complex of mitochondria. EMBO J. 19, 4895-4902 (2000).

45. Vilardell, J. \& Warner, J. R. Ribosomal protein L32 of Saccharomyces cerevisiae influences both the splicing of its own transcript and the processing of rRNA. Mol. Cell. Biol. 17, 1959-1965 (1997).

46. Acker, M. G., Kolitz, S. E., Mitchell, S. F., Nanda, J. S. \& Lorsch, J. R. Reconstitution of yeast translation initiation. Methods Enzymol. 430, 111-145 (2007).

47. Stojanovski, D., Pfanner, N. \& Wiedemann, N. Import of proteins into mitochondria. Methods Cell. Biol. 80, 783-806 (2007).

48. Wegrzyn, R. D. et al. A conserved motif is prerequisite for the interaction of NAC with ribosomal protein L23 and nascent chains. J. Biol. Chem. 281, 2847-2857 (2006).

49. Pfanner, N. \& Meijer, M. Protein sorting. Pulling in the proteins. Curr. Biol. 5, 132-135 (1995).

50. Longtine, M. S. et al. Additional modules for versatile and economical PCR-based gene deletion and modification in Saccharomyces cerevisiae. Yeast 14, 953-961 (1998).

\section{Acknowledgements}

We thank Professors Ami Aronheim, Birgitta Beatrix, Martine Collart, Elke Deuerling, Michael Glickman, Arnon Henn, Ophry Pines, Doron Rapaport and Jonathan Warner for plasmids and antibodies. We thank Stephen Michnick for the PCA library. The advice and guidance of Ying Zhang and Professor Sabine Rospert in the import assays are highly 
appreciated. This work was funded by an ISF grants number 1193/09 and 1096/13. Y.C. was supported by a Karen Siem Fellowship and Y.C. and M.S. are supported by an ERC StG 260395.

\section{Author contributions}

C.L. and Y.A. conceived the project; C.L. performed the Co-IP, ribosomal and mitochondrial association assays and the import assays; Y.C. and M.S. performed and analysed the DHFR PCA screen and the in vivo imaging; A.A.-L. performed some of the biochemical purifications; C.L., M.S. and Y.A. wrote the paper. All the authors discussed and analysed the data.

\section{Additional information}

Supplementary Information accompanies this paper at http://www.nature.com/ naturecommunications
Competing financial interests: The authors declare no competing financial interests.

Reprints and permission information is available online at http://npg.nature.com/ reprintsandpermissions/

How to cite this article: Lesnik, C. et al. OM14 is a mitochondrial receptor for cytosolic ribosomes that supports co-translational import into mitochondria. Nat. Commun. 5:5711 doi: 10.1038/ncomms6711 (2014).

\section{(c) (i)}

This work is licensed under a Creative Commons Attribution 4.0 International License. The images or other third party material in this article are included in the article's Creative Commons license, unless indicated otherwise in the credit line; if the material is not included under the Creative Commons license, users will need to obtain permission from the license holder to reproduce the material. To view a copy of this license, visit http://creativecommons.org/licenses/by/4.0/ 


\section{Corrigendum: OM14 is a mitochondrial receptor for cytosolic ribosomes that supports co-translational import into mitochondria}

Chen Lesnik, Yifat Cohen, Avigail Atir-Lande, Maya Schuldiner \& Yoav Arava

Nature Communications 5:5711 doi: 10.1038/ncomms6711 (2014); Published 9 Dec 2014; Updated 30 Mar 2015

This Article was originally published without the accompanying Supplementary Table 1. This has now been corrected in the HTML version of the Article; the PDF was correct from the time of publication. 